\title{
MOBILE LEARNING IN OUTDOOR SETTINGS: A SYSTEMATIC REVIEW
}

\author{
Johan Stymne \\ Stockholm University, Department of Computer and Systems Sciences/DSV \\ SE-164 07 Stockholm, Sweden
}

\begin{abstract}
Learning with mobile technology, or mobile learning, is gaining more and more interest in education. One example is mobile learning in outdoor settings, where mobile technology can support students' interaction with the physical environment. To understand how mobile technology has been used in learning activities in outdoor settings, a systematic review was carried out. A number of reviews on mobile learning and on specific sub-areas such as language learning or computer education have been published in scientific journals and conferences. So far, however, no systematic review has focused on mobile learning in outdoor settings. To address this problem and to guide the review the following research questions were posed: "Which are the educational subjects and educational levels in mobile learning in outdoor settings?" and "What types of technologies and methods for data collection and annotation are used in mobile learning in outdoor settings?". In total 87 articles were included in this review. The conclusions include that biology was the most common subject, primary or elementary school the most common educational levels, GPS was the major technology used for positioning and navigation, AR was the most common technology used for augmenting the outdoor learning environment, and taking photos and taking notes was the most common methods for data collection in outdoor settings. Building on the conclusions of this review and on previous reviews, suggestions are made for future research.
\end{abstract}

\section{KEYWORDS}

Mobile Learning in Outdoor Settings, Mobile Learning, Outdoor Learning, Systematic Review, State of the Art

\section{INTRODUCTION}

Mobile phones can be used for learning that is contextualized, making the physical environment, together with the temporal, social, and cultural environments relevant in learning activities (Frohberg, Göth, \& Schwabe, 2009; Sharples, Taylor, \& Vavoula, 2007; Tan, et al., 2018). One type of mobile learning, where these different environments, and especially the physical environment, can be included in learning activities, is mobile learning in outdoor settings.

Rikala (2015) has proposed that: "the aim of mobile learning should be to offer new opportunities for learning that extend learning beyond the traditional teacher-led and classroom-bound approaches. Learners with mobile devices can go into the field, interact with other people, and gain concrete knowledge instead of sitting in the classroom and listening to a teacher." (p.69). One step towards this aim, could be to review how mobile learning has been used in outdoor settings.

So far, two reviews of mobile learning in general have been published by Frohberg et al. (2009) and Wingkvist \& Ericsson (2011). These reviews were intended to cover the whole research field. Frohberg et al. (2009) focused their analysis of 102 research projects on five dimensions: context, tools, control, communication, subject and objective. Wingkvist \& Ericsson (2011) reviewed 114 articles from the World Conference on Mobile and Contextual Learning (mLearn) 2005, 2007 and 2008, focusing their analysis on research purpose and research method. With the growth of the research field of mobile learning these general reviews are giving way for more specific reviews. In recent years, reviews on different aspects of the mobile learning research field are appearing, such as Almeida \& Araújo Jr (2016) focusing on science and mathematics, Crompton et al. (2016) focusing on science, Anohah et al. (2017) focusing on computer education, Kukulska-Hulme and Viberg (2018) focusing on second language acquisition, Crompton et al. (2017) focusing on educational levels from pre-kindergarten to grade 12, and Suárez et al. (2018) focusing on mobile inquiry-based learning. Tan et al. (2018), reviewed studies on mobile inquiry-based learning, however only from two countries: The Netherlands and Singapore. So far there has been no systematic review focusing on mobile learning in outdoor settings. In identifying gaps in previous research, Crompton et al. 
(2017) also suggested that there is a need for more reviews on mobile learning: "Further reviews are needed to build on this study and add to the paucity of research in this area." (p. 61).

This article presents a systematic review of research where mobile phones and other mobile devices have been used to support contextualized learning in outdoor settings. This may be of interest to the mobile learning research community as it identifies gaps in current research on mobile learning in outdoor settings.

To summarise, there have been a number of reviews on mobile learning in general and on specific subject areas such as second language acquisition or on specific learning approaches such as inquiry-based learning, however no systematic review has focused specifically on mobile learning in outdoor settings.

To address this problem and to guide the review and analysis the following research questions are posed:

- Which are the educational subjects and educational levels in mobile learning in outdoor settings?

- What types of technologies and methods for data collection and annotation are used in mobile learning in outdoor settings?

\section{BACKGROUND}

Many descriptions and definitions of mobile learning have been suggested, and as the research area and the mobile technologies have evolved, so have the definitions. Sharples et al. (2007) suggests a definition of mobile learning as: "the processes of coming to know through conversations across multiple contexts amongst people and personal interactive technologies". The definition is adopted to add focus to this review.

In reviewing research on outdoor learning, Rickinson et al. (2004), describes one category of outdoor learning activities as "fieldwork and outdoor visits", giving examples of outdoor settings such as: "...field study centres, nature centres, farms, parks or gardens.". These examples of outdoor settings are in line with the focus of this review.

In a review of the use of mobile learning in science, Crompton et al. (2016) reviewed 49 articles from 2000 onwards. Among the results they presented were science area, educational level, countries of study, and types of mobile devices. The most common science area was life science (67\%), including for example biology. The most common educational level was elementary school (53\%) followed by high school (22\%). Taiwan $(43 \%)$, followed by USA $(16 \%)$ were the most common countries. Mobile phones and PDAs were the most common mobile devices (30\% each). $15 \%$ was reported as mobile devices in general, digital camera made up 9\%, iPad 5\%, and handheld, tablet and iTouch had a share of $4 \%$ each. In the discussion they note that the specific type of mobile phone or PDA was rarely mentioned in the articles, or even just mentioned as mobile device or handheld. Crompton et al. (2016) suggest that: “...those interested in doing future research regarding the use of mobile technologies need not focus on the specific type of mobile device, but rather on the multifunctionality and accessibility of the device." (p. 158). Crompton et al. (2017) reviewed 113 articles on mobile learning from pre-kindergarten to grade 12 (PK-12), from 2010 to 2015. The results show, for example, that the most common subject area was science $(56 \%)$, followed by literacy $(21 \%)$, and mathematics $(10 \%)$. The most common educational level was elementary school (46\%), followed by middle school (29\%), and high school (19\%). The most common mobile device was mobile phone (34\%), followed by PDA $(22 \%)$, tablet (16\%), iPad (11\%), ebook (2\%), and iPod (1\%). Taiwan (35\%) was the most common country, followed by Singapore $(9 \%)$, and USA $(8 \%)$.

Crompton et al. $(2017 ; 2016)$ present clear results on the educational contexts of mobile learning in science and mobile learning in PK-12 education, and which mobile devices are used. There is a knowledge gap, however, in which technologies are used apart from mobile devices. There is also a knowledge gap in what the educational subjects and educational levels are for mobile learning in outdoor settings.

Suárez et al. (2018) reviewed 62 studies on mobile inquiry-based learning from 2006 to April 2016. They extracted data in five categories: direct instruction, access to content, data collection, peer-to-peer communication, and contextual support. In their results, location guidance was described as part of the direct instruction category. Location guidance, by using for example GPS, RFID or QR codes, was reported in 27 of the studies. Digital artifacts triggered by GPS and AR was reported as fixed content, as part of the access to content category. Fixed content was reported in 25 of the studies. For the data collection category, capturing multimedia data or taking notes was described as cooperative data collection. Cooperative data collection was reported in 57 of the studies. In a meta-analysis they mapped the five categories to six types of agency supported by the mobile technology in inquiry-based learning. One result of the review and meta-analysis is an overview of what kind of learner agency can be supported by different parts of a mobile inquiry-based learning activity. 
Suárez et al. (2018) present results on how technologies like GPS, AR and taking notes on mobile devices are used in mobile inquiry-based learning. They present their results in their five categories. There is a knowledge gap, however, in what technologies are used, reported separately, and for mobile learning in outdoor settings. A systematic review could contribute to filling these knowledge gaps.

\section{METHOD}

The PRISMA statement (Liberati, et al., 2009) gives guidelines for reporting systematic reviews of evaluations of interventions. This systematic review follows Liberati et al. (2009) in that it presents which information sources were used, search strategy, study selection, and data collection process. The information sources that were used were research databases and conference proceedings. The search strategy used both keyword search and manual search. The study selection used six selection criteria and three inclusion and exclusion criteria. The data collection process used eight categories for data extraction.

\subsection{Database Selection and Search Strategy}

Database searches were carried out using ERIC via EBSCOhost, Scopus and DBLP. The Title, Abstract and Keyword fields were included in this search. As a complement the main conferences focusing on mobile learning were selected for free text search: World Conference on Mobile and Contextual Learning (mLearn), and the International Conference on Mobile Learning.

The search strategy used was a combination of keyword search using databases, manual search and reference list search. Two sets of keywords were used in the keyword search, mobile device-related keywords and outdoor learning-related keywords. The mobile device-related keywords were identified from previous mobile learning reviews: Frohberg et al. (2009), Wingqvist \& Ericsson (2011), and Crompton et al. (2017; 2016), and the outdoor learning-relaed keywords were identified from outdoor learning reviews: Rickinson et al. (2004), and Fiennes et al. (2015).

As the articles should include both mobile technology and learning in outdoor settings the search was done using the following combination of mobile technology related and outdoor learning related keywords:

- ERIC, Scopus (Title, Author keywords, Abstract): ("mobile learning" OR m-learning OR "mobile phone*" OR "mobile device*" OR "mobile technolog*" OR smartphone OR handheld OR pda* OR "augmented reality") AND ("outdoor * learning*" OR "outdoor * lesson*" OR "outdoor * education*" OR "field trip*" OR excursion* OR adventur* OR "nature visit*" OR bushcraft*).

- DBLP (Title, Author keywords, Abstract): Manual combination of the keywords.

- World Conference on Mobile and Contextual Learning (Full text), International Conference on Mobile Learning (Title, Author keywords, Abstract): Manual combination of the outdoor learning-related keywords without wildcards.

\subsection{Selection Criteria}

The overall focus for the review was: "Original empirical research on the use of mobile learning in outdoor settings". The articles were published between 2004 and 2019. This timeframe was chosen because the first studies on mobile learning in outdoor settings identified were published in 2004, and the selection includes articles published until December 2019. The geographical scope was international. All educational levels were included, ranging from pre-kindergarten to higher education including postgraduate level. Articles from all countries were included in the search, however only articles published in English were included in the selection. Only published articles that had been peer-reviewed were included.

\subsubsection{Inclusion and Exclusion Criteria}

- For articles reporting on the same empirical study, only the last published article was included in the review.

- Included articles needed to present results from empirical tests with representative learners using some mobile technology. This means that articles presenting results from tests with colleagues, or focusing on performance, technical functionality or usability of a system without also focusing on mobile learning were excluded. 
- Only articles presenting studies where some aspect of the mobile technology, hardware or software, was designed for a specific learning activity were included. Studies using off-the-shelf mobile technology or with apps not intended for specific learning activities were excluded. Studies using laptop computers were also excluded.

\subsection{Study Selection}

643 articles were identified through database search and manual search: ERIC (118), Scopus (414), DBLP (18), World Conference on Mobile and Contextual Learning (63), International Conference on Mobile Learning (11). After duplicates removal and screening 145 articles remained. In the end, 87 articles met the criteria for inclusion and were included in this review.

\subsection{Data Extraction}

The following data was extracted from the published articles: name of study, educational subject(-s), educational level(-s), country, mobile device(-s), technology used for positioning or navigation, technology used for augmenting the outdoor learning environment, and data collection or annotation method(-s). Each of the extracted data is described in Table 1. The database with extracted data and full references can be accessed from here: http://johan.blogs.dsv.su.se/data/.

Table 1. Description of extracted data

\begin{tabular}{|l|l|}
\hline Data & Description \\
\hline Name & $\begin{array}{l}\text { Name of study, or where not available, Name of project or system or } \\
\text { course }\end{array}$ \\
\hline Educational subject(-s) & Educational subject(-s) \\
\hline Educational level(-s) & $\begin{array}{l}\text { Pre-kindergarten, kindergarten and pre-school (typical age 1-6 years } \\
\text { old), primary school or elementary school (6-12) secondary school or } \\
\text { middle school (12-16), high school (16-18), higher education (18+) }\end{array}$ \\
\hline Country & Country where the empirical study took place \\
\hline Mobile device(-s) & Mobile phone, PDA, Tablet \\
\hline Technology used for positioning or navigation & GPS, QR, RFID, WIFI, Compass, Numerical code \\
\hline Technology used for augmenting & AR (Augmented Reality), 3D model, Image recognition \\
\hline Method(-s) for data collection or annotation & Photo, Notes, Audio, Video, Probe \\
\hline
\end{tabular}

The name of the study was not always reported in the articles. In those cases the name of the project, the name of the system, or the name of the course was extracted.

The educational levels differ from country to country. That is why two or more levels can belong to the same category in the data extraction phase. Differences in educational levels are also the reason why typical ages are given instead of exact ages.

\section{RESULTS}

To give a backdrop to the results, the number of articles per year and per country are presented. The number of articles per year on mobile learning in outdoor settings has increased, from two articles, which was the lowest number, in 2004, 2006 and 2007 to nine, which was the highest number, in 2015 and 2018.

The top seven countries or regions to publish on mobile learning in outdoor settings were (number of articles in parenthesis): Taiwan (26), UK (7), Sweden (6), USA (6), Germany (5), Singapore (5), and Finland (4). Out of the 87 articles in this review, 30\% were from Taiwan. The articles from Taiwan were published between 2005 and 2019. The articles from the UK were published from 2004, however the last article was published in 2012. The articles from Sweden were published between 2008 and 2015, and from USA between 2011 and 2018. The articles from Germany were published between 2005 and 2018, from Singapore between 2007 and 2015, and from Finland between 2012 and 2018. 
There were articles from 16 more countries or regions: Greece (3), Israel (3), Japan (3), Brazil (2), Hong Kong (2), Italy (2), Portugal (2), Spain (2), Australia (1), Austria (1), Czech Republic (1), Estonia (1), Indonesia (1), Ireland (1), Norway (1), and South Africa (1).

\subsection{Educational Subjects and Educational Levels}

The five most common subjects in the reviewed articles were (number of articles in parenthesis): biology (38), history (14), mathematics (9), language (7), geography (5) and geology (5) (see Table 2). The biology subject, reported in 38 articles, was much more common than any of the other subjects. Subjects reported in between 1-4 articles were (number of articles in parenthesis): natural science (4), local culture (3), orientation (3), science (2), health education (2), physics (2), sustainability (2), tourism (2), archaeology (1), computer science (1), economy (1), information and communication technology (1), pedagogy (1), and technology (1).

Table 2. Subjects, number of articles and years of publication

\begin{tabular}{|l|l|l|}
\hline Subject & Number of articles & Years of publication \\
\hline Biology & 38 & $2004-2019$ \\
\hline History & 14 & $2008-2019$ \\
\hline Mathematics & 9 & $2006-2019$ \\
\hline Language & 7 & $2008-2015$ \\
\hline Geography & 5 & $2005-2013$ \\
\hline Geology & 5 & $2008-2019$ \\
\hline
\end{tabular}

Biology was also the only subject reported on in articles from the first year of the review until the last year, 2004-2019. History, mathematics and geology were represented until 2019, while language and geography were represented in the middle of the timeframe for the review: 2008-2015 and 2005-2013.

Primary school or elementary school was the most common educational level with 49 articles, see Table 3. It was more common than secondary school or middle school with 22 articles and higher education with 18 articles. No articles were from pre-kindergarten, kindergarten and pre-school.

Table 3. Number of articles and educational levels (one article from 2009 had both primary and middle school students and one article from 2019 had both primary and secondary school students).

\begin{tabular}{|l|c|c|c|c|c|}
\hline Year & $\begin{array}{c}\text { Number of } \\
\text { articles }\end{array}$ & $\begin{array}{c}\text { Pre-kindergarten, } \\
\text { kindergarten and pre-school }\end{array}$ & $\begin{array}{c}\text { Primary or } \\
\text { elementary school }\end{array}$ & $\begin{array}{c}\text { Secondary or } \\
\text { middle school }\end{array}$ & $\begin{array}{c}\text { Higher } \\
\text { education }\end{array}$ \\
\hline $2004-2019$ & 87 & 0 & 49 & 22 & 18 \\
\hline
\end{tabular}

\subsubsection{Country or Regional Comparison}

One difference between countries or regions was the subject reported in the articles. For example, the most common subject in Taiwan was biology. The subject was studied in 16 out of the 26 articles from Taiwan. The second most common subject in Taiwan, history was studied in four out of the 26 articles. Biology was also the most common subject in Germany, Singapore and Finland. In Sweden the most common subject was mathematics and in USA the most common was natural science. In UK biology and language were as common, studied in two articles each.

Another difference between countries was the educational level of participating students. For example, the most common educational level in Taiwan was elementary school. Elementary school was reported in 23 out of the 26 articles. Primary or elementary school was also the most common in Sweden, USA, Singapore and Finland. Secondary school was the most common in UK and in Germany. Higher education was not the most common educational level in any of the top seven countries, however it was the second most common educational level in Taiwan, UK, USA, Germany, and Finland. All students from higher education were undergraduate students; no students were from the graduate level.

One last difference between countries or regions was the size of student groups, ranging from one student, learning individually, to nine students in a group. Out of the top seven countries or regions, the most common group size in Taiwan and Singapore was one student, corresponding to individual learning. This group size was used in 20 out of the 26 articles from Taiwan. The second most common group size for Taiwan was five students in each group. This group size was used in four of the 26 articles. In UK and USA the most common group size was two students, in Sweden it was three students and in Germany and Finland it was two or three students. 


\subsection{Mobile Devices}

Mobile phones were the most common mobile devices, see Table 4. The use of PDAs has decreased, going from 18 in the first eight years between 2004 and 2011 to four in the last eight years between 2012 and 2019. However, the use of mobile phones has increased in the same time period, going from 17 between 2004 and 2011 to 32 between 2012 and 2019. The use of tablets has also increased, going from two between 2004 and 2011 to 20 between 2012 and 2019.

Table 4. Number of mobile phones, PDAs and tablets used in the articles (two or more mobile devices in six articles)

\begin{tabular}{|l|c|c|c|c|}
\hline Year & Number of articles & Mobile phone & PDA & Tablet \\
\hline $2004-2019$ & 87 & 49 & 22 & 22 \\
\hline
\end{tabular}

Mobile phones are used in much the same way as PDAs in mobile learning, and have gradually replaced them. DVD or smart watch was not part of the data extraction, however DVD was used as mobile device in one of the reviewed articles. Smart watch was not used in any of the reviewed articles.

\subsection{Positioning or Navigational Technologies}

GPS was the most common technology used for positioning or navigation to learning material in outdoor settings, see Table 5. It was reported in 46 articles, published between 2004 and 2019. The second most common technology was QR codes, with 17 articles, published between 2007 and 2018.

Table 5. Positioning or navigational technology used, with number of articles and years of publication

\begin{tabular}{|l|c|c|}
\hline Positioning or navigational technology & Number of articles & Years of publication \\
\hline GPS & 46 & $2004-2019$ \\
\hline QR & 17 & $2007-2018$ \\
\hline RFID & 7 & $2007-2019$ \\
\hline WIFI & 3 & $2005-2008$ \\
\hline Compass & 3 & $2012-2019$ \\
\hline Numerical code & 2 & 2008 and 2015 \\
\hline
\end{tabular}

The third most common technology was RFID, with 7 articles, published between 2007 and 2019. WIFI networks were used in three articles, published in 2005 and 2008, and compass was used in three articles, published in 2012, 2015 and 2019. Numerical codes to type in manually were used for positioning or navigation in two articles, published in 2008 and 2015.

In 20 articles, no technology was used for positioning or navigation. In 55 articles one technology was used for positioning or navigation. 12 articles used more than one. No articles used three or more technologies for positioning or navigation.

\subsection{Augmenting Technologies}

AR was the most common technology used for augmenting the outdoor learning environment, see Table 6.

Table 6. Augmenting technology used, with number of articles and years of publication

\begin{tabular}{|l|c|c|}
\hline Augmenting technology & Number of articles & Years of publication \\
\hline AR & 14 & $2009-2019$ \\
\hline 3D model & 9 & $2008-2019$ \\
\hline Image recognition & 3 & $2005-2012$ \\
\hline
\end{tabular}


AR was used in 14 articles published between 2009 and 2019. The second most common technology was 3D models, with 9 articles, published between 2008 and 2019. The third most common technology was Image recognition, with 3 articles, published between 2005 and 2012.

\subsection{Methods for Data Collection or Annotation}

Taking photos and taking notes were the most common methods used by the students for data collection or annotation, see Table 7. Taking photos was used in 40 articles, published between 2005 and 2019. Taking notes was used in 20 articles, published between 2005 and 2018. The third most common method was recording audio, with 13 articles, published between 2008 and 2018. The fourth most common method was recording video, with 10 articles, published between 2008 and 2019. The fifth most common method was probing, for example by using specific devices for measuring water quality, air temperature or carbon monoxide. Probes were used in 6 articles, published between 2004 and 2018.

Table 7. Methods for data collection or annotation, with number of articles and years of publication

\begin{tabular}{|l|c|c|}
\hline $\begin{array}{l}\text { Methods for data } \\
\text { collection or annotation }\end{array}$ & $\begin{array}{c}\text { Number of } \\
\text { articles }\end{array}$ & $\begin{array}{c}\text { Years of } \\
\text { publication }\end{array}$ \\
\hline Photo & 40 & $2005-2019$ \\
\hline Notes & 20 & $2005-2018$ \\
\hline Audio & 13 & $2008-2018$ \\
\hline Video & 10 & $2008-2019$ \\
\hline Probe & 6 & $2004-2018$ \\
\hline
\end{tabular}

\section{DISCUSSION AND CONCLUSION}

One interpretation of the increasing number of articles published per year is that the research interest in mobile learning in outdoor settings is still growing. In the first few years of this review, there were only two and three studies published on mobile learning in outdoor settings, whereas in the last few years of the review there were between five and nine studies published each year.

Most of the articles in this review were from Taiwan. This confirms the results of the review of mobile learning in science by Crompton et al. (2016), who found that Taiwan was the most common country of study. It also confirms the results of Crompton et al. (2017), who reviewed mobile learning in PK-12 education, finding that Taiwan had the most publications. One difference was that the second most common country of study in this review was UK compared to USA in second place in Crompton et al. (2016) and Singapore in Crompton et al. (2017). Notable is that UK has the second highest number of articles published on mobile learning in outdoor settings, even though the last publication from UK is from 2012.

The first research question: "Which are the educational subjects and educational levels in mobile learning in outdoor settings?" can be answered with the following: The most common educational subject for mobile learning in outdoor settings was biology followed by history and mathematics. That biology was the most common subject is in line with Crompton et al. (2016). The most common educational level for mobile learning in outdoor settings was primary or elementary school. This confirms the results of Crompton et al. (2017; 2016). There are differences between countries or regions regarding common subjects, educational levels, and group sizes in mobile learning in outdoor settings. In five of the top seven countries biology was the most common subject. In Sweden mathematics was most common and in USA natural science was most common. In five of the top seven countries primary or elementary school was the most common educational level. In UK and Germany secondary school were the most common. In Taiwan, UK, USA, Germany, and Finland higher education was the second most common educational level. In five of the top seven countries groups of two to three students was the most common. In Taiwan and Singapore individual learning was the most common.

The second research question: "What types of technologies and methods for data collection and annotation are used in mobile learning in outdoor settings?" can be answered as follows: Mobile phones or PDAs were the most common mobile devices. This confirms the results of Crompton et al. (2017; 2016). The use of tablets has increased during the last eight years. GPS was the most common technology for positioning or navigation, reported in 46 articles, followed by $Q R$ codes (17), and RFID (7). That positioning or 
navigation was common in outdoor mobile learning activities is in line with the results of Suárez et al. (2018), in describing location guidance as being common in mobile inquiry-based learning. $A R$ was the most common technology for augmenting the outdoor learning environment, reported in 14 articles. Finally, taking photos, reported in 40 articles, followed by taking notes (20), and recording audio (13), were the most common data collection or annotation methods. This is also in line with the results of Suárez et al. (2018), who describe cooperative data collection as being common in mobile inquiry-based learning.

A number of gaps have been identified in this review. First, the most common subject was biology. Future studies of mobile learning in outdoor settings may focus on other subjects further down the list. Second, all of the articles had students from primary or elementary school to higher education. Studies of mobile learning in outdoor settings in pre-kindergarten, kindergarten or pre-school are needed. Third, mobile phones were the most common devices. Tablets were increasingly being used. Studies using smart watches are still lacking. Fourth, few studies used two technologies for positioning or navigation and no articles used three or more. Future studies could support the whole range from small-scale to large-scale navigation and positioning by using two or more technologies, available in new mobile phones. Fifth, in many studies students took photos and notes by using mobile devices or other mobile technology. Only ten articles reported that video was used for data collection, and six articles reported that probes were used. More studies could use video or probes for data collection.

This study has a number of limitations. Even though the review method was applied in a thorough way, one limitation is that there may be articles fulfilling the inclusion criteria that were not identified through the database and manual search. Another limitation is that no inter-rater reliability check has been performed. One last limitation is that only articles published in English were included in the review.

\section{REFERENCES}

Almeida, R. R., \& Araújo Jr, C. F. (2016). Mobile Learning in Science and Mathematics Teaching: A Systematic Review Mobile and Blended Learning Innovations for Improved Learning Outcomes (pp. 277-296): IGI Global.

Anohah, E., Oyelere, S. S., \& Suhonen, J. (2017). Trends of mobile learning in Computing Education from 2006 to 2014: A systematic review of research publications. International Journal of Mobile and Blended Learning (IJMBL), 9(1), 16-33.

Crompton, H., Burke, D., \& Gregory, K. H. (2017). The use of mobile learning in PK-12 education: A systematic review. Computers and Education, 110, 51-63.

Crompton, H., Burke, D., Gregory, K. H., et al. (2016). The Use of Mobile Learning in Science: A Systematic Review. Journal of Science Education and Technology, 25(2), 149-160.

Fiennes, C., Oliver, E., Dickson, K., et al. (2015). The existing evidence-base about the effectiveness of outdoor learning. Institute of Outdoor Learning: London, UK.

Frohberg, D., Göth, C., \& Schwabe, G. (2009). Mobile Learning projects - a critical analysis of the state of the art: Original article. Journal of Computer Assisted Learning, 25(4), 307-331.

Kukulska-Hulme, A., \& Viberg, O. (2018). Mobile collaborative language learning: State of the art. British Journal of Educational Technology, 49(2), 207-218.

Liberati, A., Altman, D. G., Tetzlaff, J., et al. (2009). The PRISMA statement for reporting systematic reviews and metaanalyses of studies that evaluate health care interventions: Explanation and elaboration. PLoS Medicine, 6(7).

Rickinson, M. (2004). A review of research on outdoor learning: Field Studies Council.

Rikala, J. (2015). Designing a mobile learning framework for a formal educational context. Jyväskylä studies in computing(220).

Sharples, M., Taylor, J., \& Vavoula, G. (2007). A Theory of Learning for the Mobile Age. In R. Andrews \& C. A. Haythornthwaite (Eds.), The SAGE handbook of e-learning research. Thousand Oaks, Calif.: SAGE Publications.

Suárez, Á., Specht, M., Prinsen, F., et al. (2018). A review of the types of mobile activities in mobile inquiry-based learning. Computers \& Education, 118, 38-55.

Tan, E., Rusman, E., Firssova, O., et al. (2018). Mobile Inquiry-based Learning: Relationship among levels of inquiry, learners' autonomy and environmental interaction. Paper presented at the World Conference on Mobile and Contextual Learning 2018. Retrieved from https://www.learntechlib.org/p/184919

Wingkvist, A., \& Ericsson, M. (2011). A Survey of Research Methods and Purposes in Mobile Learning. International Journal of Mobile and Blended Learning (IJMBL), 3(1), 1-17. 